\title{
Analysis and Design of Power Management Scheme for an On-board Solar Energy Storage System
}

\author{
W. Jiang ${ }^{1}$, F.Y. Yu ${ }^{1}$, Z.Y. Lin $^{2}$, G.F. Wu ${ }^{1}$, H. Chen ${ }^{1}$, S Hashimoto ${ }^{3}$ \\ ${ }^{1}$ Department of Electrical Engineering \\ Yangzhou University, China \\ Email: jiangwei@yzu.edu.cn \\ ${ }^{1}$ Department of Electrical, Electronic \& Power Engineering \\ Aston University, UK \\ Email: z.lin@ieee.org \\ ${ }^{3}$ Department of Electronic Engineering \\ Gunma University, Japan \\ Email: hashimotos@gunma-u.ac.jp
}

\begin{abstract}
This paper investigates the power management issues in a mobile solar energy storage system. A multi-converter based energy storage system is proposed, in which solar power is the primary source while the grid or the diesel generator is selected as the secondary source. The existence of the secondary source facilitates the battery state of charge detection by providing a constant battery charging current. Converter modeling, multi-converter control system design, digital implementation and experimental verification are introduced and discussed in details. The prototype experiment indicates that the converter system can provide a constant charging current during solar converter maximum power tracking operation, especially during large solar power output variation, which proves the feasibility of the proposed design.
\end{abstract}

\section{INTRODUCTION}

Photovoltaic is one of the most environmentally friendly power generation technologies. To utilize PV power effectively, two solutions are usually applied. The first solution is to provide ac power conditioning to the solar panel, converting variable dc power to ac power; the load can be either local ac load or the grid [1]-[4]. The other solution is to integrate solar power into the dc power networks for dc applications [5]-[7] , such as sensors, fans and actuators. As the maximum solar power output is affected by the irradiation level and atmosphere conditions, corresponding methods have to be adopted in different applications. Maximum power point tracking (MPPT) algorithms [8][9] are the software solutions to secure efficient usage of solar power, beyond the algorithmic method additional energy storages will be added to balance the load and source power [10][11].

Due to electrification of modern vehicle, the electrical power demand on board is increasing. Solar power as one clear and portable option is gaining more and more attentions in vehicular applications, such as caravan and yacht. With reasonable space and cost, on-board solar power can supply the balance-of-plant in the form of dc power without leash the power of the drive train.

This paper propose an on-board solar energy storage system for vehicular applications, which is powered by hybrid sources [12]. Multi-converter based structure is proposed, in which solar power is the primary source while the grid or the diesel generator as the secondary source. The existence of the secondary source facilitates the battery state of charge (SOC) detection by providing a constant battery charging current. Converter modeling, multi-converter control system design, digital implementation and experimental verification are introduced and discussed in details. The prototype experiment indicates that the converter system can provide a constant charging current during solar converter maximum power tracking operation, especially during large solar power output variation.

\section{ON BOARD SOLAR ENERGY STORAGE SYSTEM}

The on-board solar energy storage system for vehicular application is proposed in Figure 1. The battery pack is the main energy buffer in the system. There are two input sources, one is the on-board solar panel; the other one is the multiplexed grid and diesel generator. The solar power is conditioned by a dc-dc converter A and is transferred to the battery pack. The voltage from the grid or diesel generator is converted into a low dc voltage, which is feeding the down-stream battery charger B as well as the load bus. A source discriminator is implemented with two diodes, which naturally commutate based on the availability of the grid/diesel power (external source); when the external power is available, the battery channel is commutated to OFF state, the external source will supply the load bus; if the external source is disconnected, the solar powered battery pack will kick in and supply the on-board load. The local loads are connected to the load bus either directly or by the point-of-load converters. 
As indicated in the figure, solar converter A and grid/diesel power converter B will supply the load current concurrently or intermittently; therefore, load sharing issue under different operating conditions are of special interest in this research.

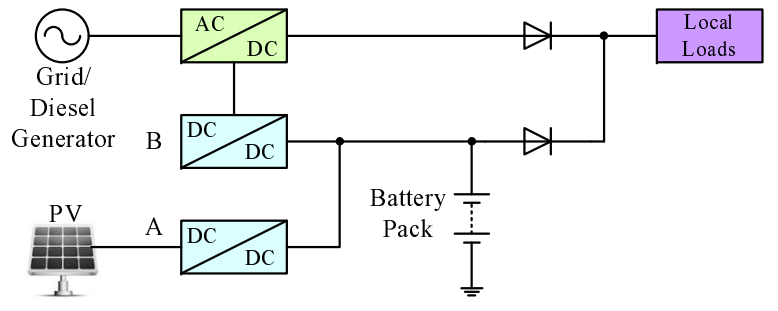

Fig. 1. solar energy storage system

\section{MOdE OF Operation}

As multiple converters are involved in energy harvesting and storage tasks, the tri-modal operation is proposed for the solar energy storage system based on the availability and stateof-charge (SOC) of the battery. In mode A, only solar panel is charging the battery, the on-board loads are supplied by the battery, converter A is working under input power control and tracking the maximum power of the solar panel. In mode $\mathrm{B}$, both grid/diesel generator and solar panel are charging the battery, the on-board loads are supplied by the grid/diesel generator converter. In mode $\mathrm{C}$, only grid/diesel generator is charging the battery, the on-board loads are supplied by the grid/diesel generator converter. In order to estimate the SOC more prescisely, terminal voltage look-up method is applied, in which the charging current is kept constant by the grid converter B.

Detailed state flow description are illustrated in Figure 2 and Table I. Due to heavy electrical load on-board, the SOC of the battery is supposed to be not high all the time. Based on the three operational modes, 6 transitional conditions are proposed. During system start-up or acceleration, there is no external plug-in power and diesel generator need to be disconnected to ensure full powertrain power; therefore, battery shall supply the load bus alone with possible assistance of the solar power. When both sources are available, converter A and B will charge the battery. When solar power is not available, the power from diesel or grid will provide power to the battery.

TABLE I. STATE FLOW CONDITIONS

\begin{tabular}{|c|l|}
\hline Transition & Condition \\
\hline 1 & system start or acceleration \\
\hline 2 & low SOC and both sources available and cruising \\
\hline 3 & low SOC and solar unavailable \\
\hline 4 & low SOC and both sources available and cruising \\
\hline 5 & low SOC and solar unavailable \\
\hline 6 & system start or acceleration \\
\hline
\end{tabular}

\section{Control System DESIGN}

The control loop is shown in Figure. 3. Since the battery voltage is kept constant over relatively long period of time,

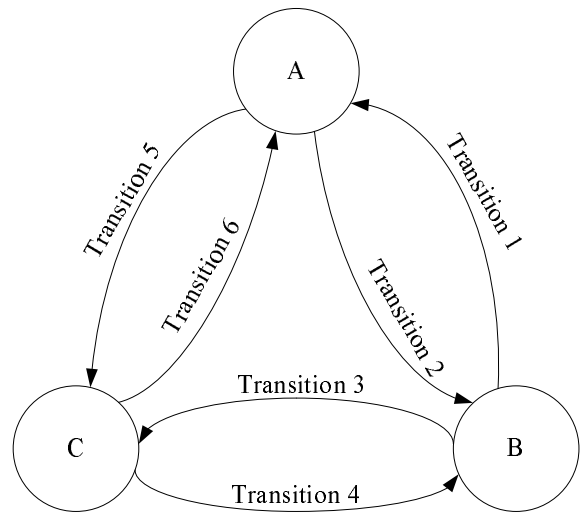

Fig. 2. solar energy storage system

modulation of duty cycle solar converter A can move the operating point of the solar panel, in which way the maximum power point can be obtained using different tracking method. In this research, perturbation and observation $(\mathrm{P} \& \mathrm{O})$ algorithm [13] is chosen. Panel terminal voltage and currents are sampled and fed into the MPPT block, duty cycle is updated at the end of each power sweep cycle $(10 \mathrm{~ms})$. The output current of solar converter A varies with solar irradiation, therefore, the grid/diesel converter B is used to keep the output current constant such that accurate battery SOC can be estimated by reading battery voltage under specific charging current. $i_{L 1}$ is the output current of solar converter $\mathrm{A}$, while $i_{L 2}$ is the output current from grid/diesel converter B. $i_{L}$, the charging current into the battery, is contributed by both converters. In order to keep the charging current constant, the current $i_{L}$ is sensed and controlled by digital signal controller, where $G_{i d x}(s)(x=1,2)$ is the duty cycle to output current transfer function, $H_{i}(s)$ is the current transducer gain, $C_{i 2}(s)$ is the current controller.

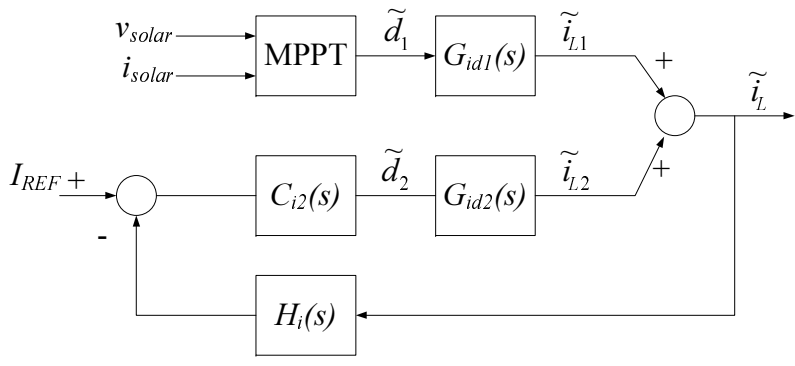

Fig. 3. control loop design

Buck topology is selected for both converters as the $12 \mathrm{~V}$ is one of the common bus voltage for vehicular application. The parameters of the buck converter are listed in Table II. The switching frequency is selected as $50 \mathrm{kHz}$.

Using state-space averaging method [14], the small signal model of the control plant can be obtained as,

$$
G_{i d}=\frac{\tilde{i}_{L}(s)}{\tilde{d}(s)}=\frac{V_{S}\left(R_{e q} C s+1\right)}{R_{e q} L C s^{2}+L s+R_{e q}}
$$


TABLE II. SYSTEM PARAMETERS

\begin{tabular}{c|c}
\hline component & Value \\
\hline$C_{1}$ & $60 \mu \mathrm{F}$ \\
\hline$L_{1}$ & $40 \mu \mathrm{H}$ \\
\hline$C_{2}$ & $60 \mu \mathrm{F}$ \\
\hline$L_{2}$ & $40 \mu \mathrm{H}$ \\
\hline
\end{tabular}

where $R_{e q}$ is the internal impedance of the on-board battery pack.

A PI controller is used to provide load current regulation; the compensated open loop transfer function is shown in the bode plot Figure 4 with $k_{p}=0.54, k_{i}=4360$; as can be seen that the cross-over frequency is $2 k H z$ with phase margin of $64^{\circ}$.

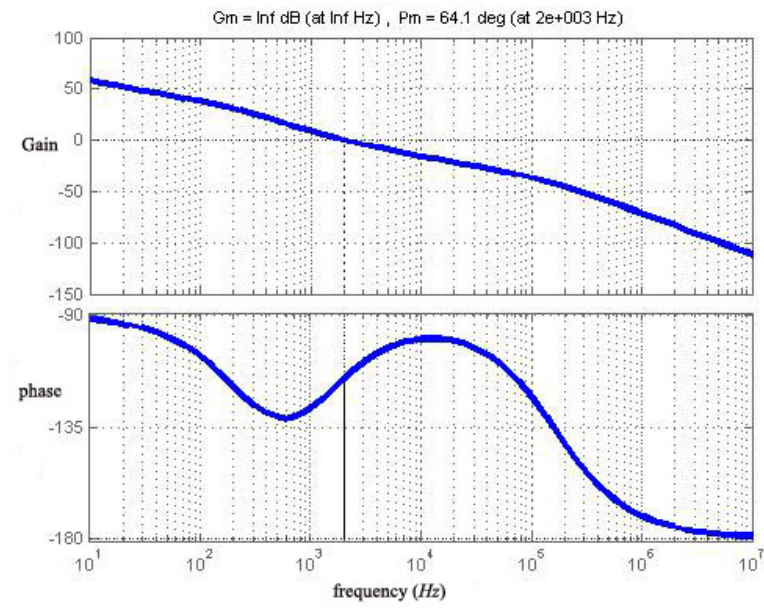

Fig. 4. open-loop transfer function bode plot

\section{EXPERIMENT RESULTS}

Hardware prototype is built and dsPIC33F DSC is used to implement the power management scheme. A $100 \mathrm{~W}$ solar panel with $V_{M P P}=28 \mathrm{~V}$ is used as the solar energy input, a $30 \mathrm{~V} 10 \mathrm{~A}$ linear power supply is used as the $\mathrm{AC} / \mathrm{DC}$ converter in Figure 1; the load is a $12 \mathrm{~V} 200 \mathrm{AH}$ lead-acid battery. The solar panel arrangement and converter test bed is shown in Figure 5.

The MPPT of the solar panel is tested under two typical conditions. The open circuit voltage method[15] is used to set the initial duty cycle while $\mathrm{P} \& \mathrm{O}$ algorithm kicks in after the start-up transient. As shown in the Figure 6(a), with the initial duty cycle setup, solar converter A can directly goes to the vicinity of the maximum power point (MPP), which only takes $7 \mathrm{~ms}$. Figure 6(b) shows MPPT operation under large solar power loss; the voltage sag before $T_{0}$ is the fully shaded condition, in which solar panel does not give any output power; the converter A reaches MPP within $1 s$ after the solar irradiation recovery.

With converter A and B connected in parallel, the current control capability of converter B is tested. The test is carried on as follows: the solar converter $\mathrm{A}$ is under inductor current $\left(I_{L 1}\right)$ control, whose current reference varies according to $9^{\text {th }}$ order PRBS. Therefore, under programmed output current reference, converter $\mathrm{A}$ is emulating the case when solar irradiation changes randomly. The test results are shown in Figure 7; the output current (charging current) is set to $15 \mathrm{~A}$, as shown in the waveform, converter B output current $\left(I_{L 2}\right)$ always compensates such that load current $I_{L}$ is kept at $15 \mathrm{~A}$.

In steady state operation, solar converter A is tracking the MPP of solar panel while converter B compensates the current loss in the total battery charging current. Figure 7 shows this test scenario, as can be found in the waveform, the summation of $I_{L 1}$ and $I_{L 2}$ keeps constant (curve $I_{L}$ ).

Figure 9 shows the testing scenario that solar panel is undergoing large solar irradiation variation. As indicated in the waveform, the power loss period is the period that the solar panel is fully covered by a blanket; converter B instantaneously balances the load power by providing all $15 \mathrm{~A}$ of load current; it be also found that this transient period is smooth due to effective control action.

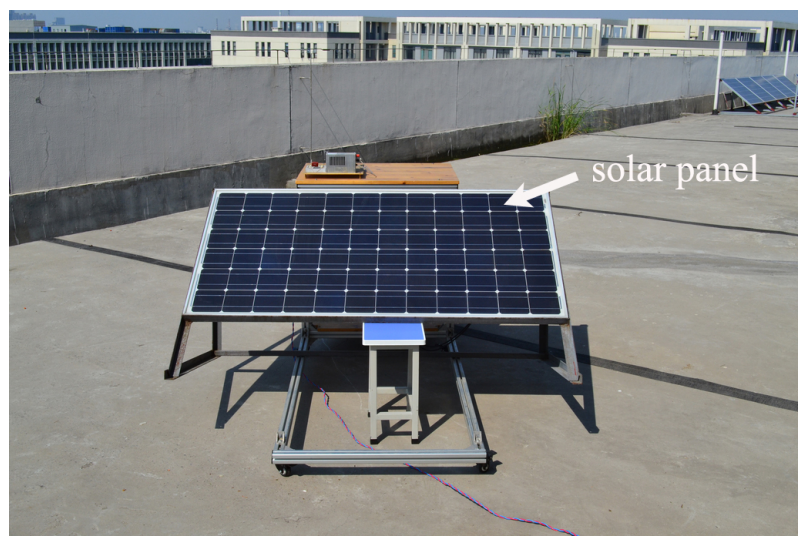

(a)

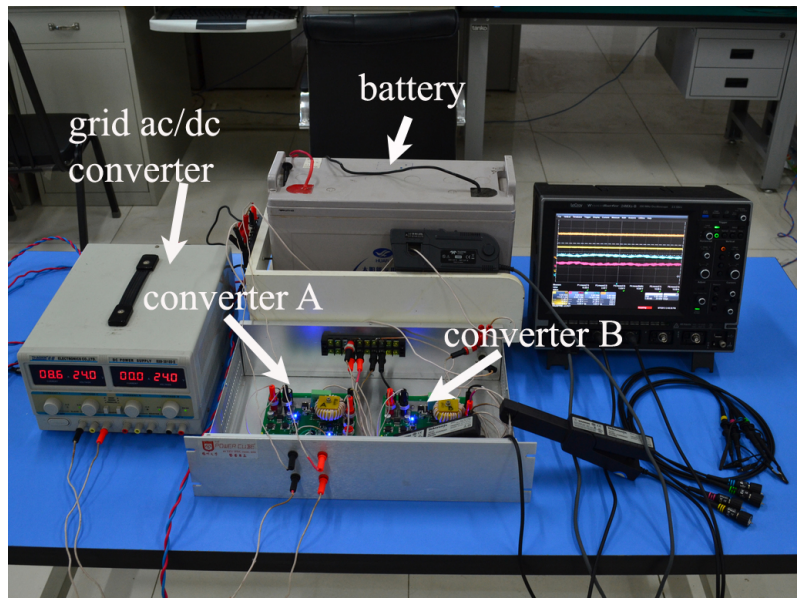

(b)

Fig. 5. experimental setup (a) mobile solar panel, (b) converter test bed 


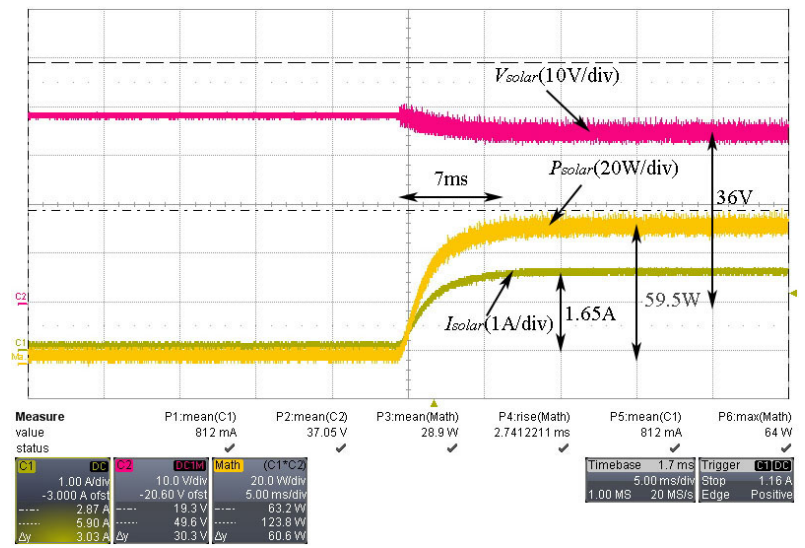

(a)

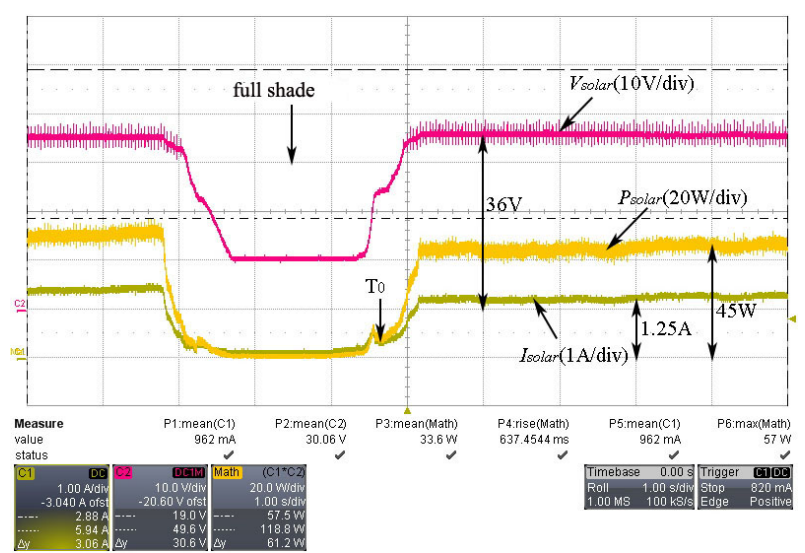

(b)

Fig. 6. maximum power point tracking test (a) start-up test $(5 \mathrm{~ms} / \mathrm{div})$, (b) abrupt irradiation change test $(1 s / d i v)$

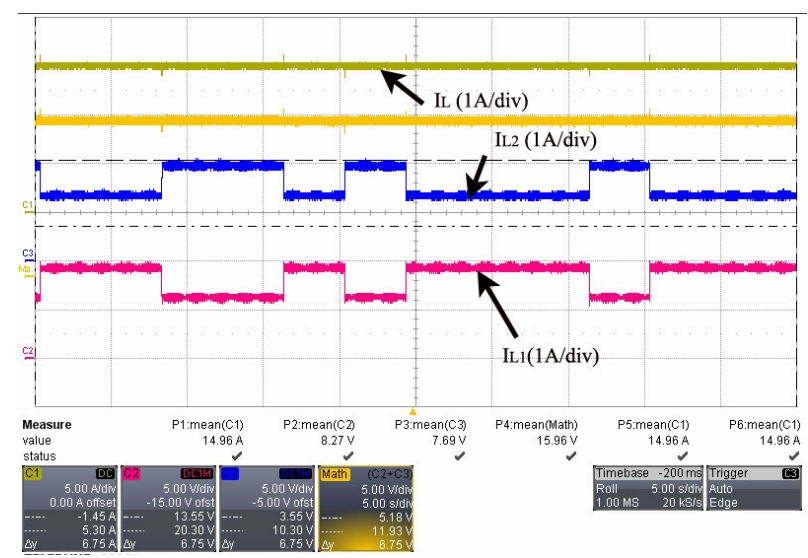

Fig. 7. load sharing test with programmed current $\left(I_{L 1}\right)$ reference $(5 s / d i v)$

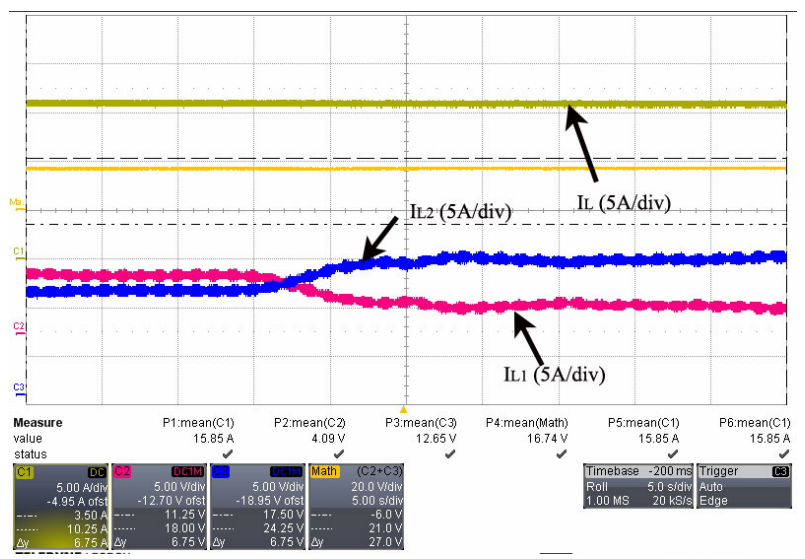

Fig. 8. steady state test with paralleled operation $(5 s / d i v)$

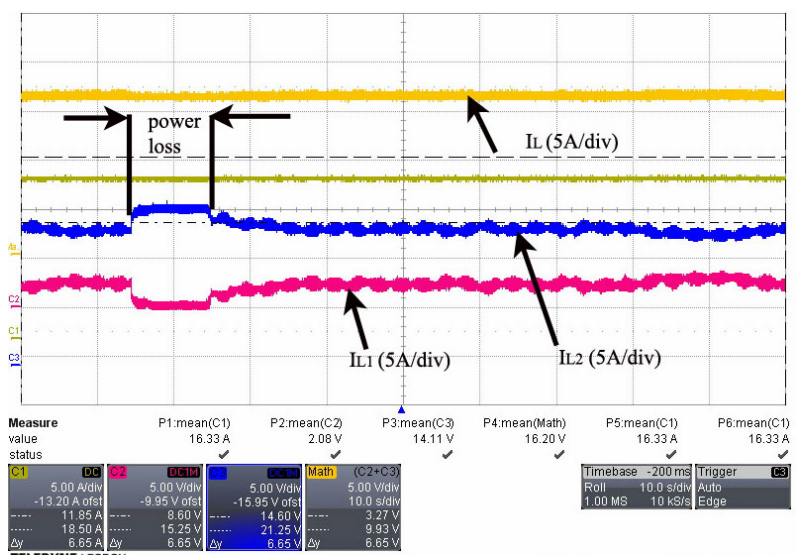

Fig. 9. Test under large solar irradiation loss $(10 s / d i v)$

\section{CONCLUSION}

In this paper, an on-board solar energy storage system is proposed for vehicular applications. This system utilize solar panel as one of the input sources, grid or diesel generator as the second source based on the availability. The system structure is proposed and power management scheme is discussed in detail. In order to fulfill constant battery charging requirements, paralleled converter is used to compensate the current variation by taking power from the grid or diesel generator. The hardware is built and the control algorithm is implemented in a DSC. The experiment indicates that the control system can keep the charging current constant during steady state operation as well as large input solar power variations.

\section{ACKNOWLEDGMENT}

This work is sponsored by National Natural Science Foundation of China (grant number 51207135), Jiangsu Natural Science Foundation (grant number BK2012266), YZU-Yangzhou City Joint Fund (grant number 2012038-10).

\section{REFERENCES}

[1] Q. Li and P. Wolfs, "A review of the single phase photovoltaic module integrated converter topologies with three different dc link configurations," IEEE Trans. Power Electron., vol. 23, no. 3, pp. 1320-1333, Mar. 2008. 
[2] B. J. Pierquet and D. J. Perreault, "A single-phase photovoltaic inverter topology with a series-connected energy buffer," IEEE Trans. Power Electron., vol. 28, no. 10, pp. 4603-4611, Oct. 2013.

[3] Y. Zhou, L. Liu, and H. Li, "A high-performance photovoltaic moduleintegrated converter (mic) based on cascaded quasi-z-source inverters (qzsi) using egan fets," IEEE Trans. Power Electron., vol. 28, no. 6, pp. 2727-2738, Jun. 2013.

[4] L. Chen, Amirahmadi, Q. Zhang, N. Kutkut, and I. Batarseh, "Design and implementation of three-phase two-stage grid-connected module integrated converter," IEEE Trans. Power Electron., vol. PP, no. 99.

[5] A. I. Bratcu, I. Munteanu, S. Bacha, D. Picault, and B. Raison, "Cascaded dc-dc converter photovoltaic systems power optimization issues," IEEE Trans. Ind. Electron., vol. 58, no. 2, pp. 403-411, Feb. 2011.

[6] B. Liu, S. Duan, and T. Cai, "Photovoltaic dc-building-module-based bipv system-concept and design considerations," IEEE Trans. Power Electron., vol. 26, no. 5, pp. 1418-1429, May 2011.

[7] Z. Liang, R. Guo, J. Li, and A. Q. Huang, "A high-efficiency pv moduleintegrated dc-dc converter for pv energy harvest in freedm systems," IEEE Trans. Power Electron., vol. 26, no. 3, pp. 897-909, Mar. 2011.

[8] T. Esram and P. L. Chapman, "Comparison of photovoltaic array maximum power point tracking techniques," IEEE Trans. Energy Convers., vol. 22, no. 2, pp. 439-449, Jun. 2007.

[9] W. Jiang and B. Fahimi, "Maximum Solar Power Transfer in Multiport Power Electronic Interface," $25^{\text {th }}$ Annual IEEE Applied Power Electronics Conference and Exposition, pp. 68-73, Feb. 2010.

[10] S. M. Lukic, J. Cao, R. C. Bansal, F. Rodriguez, and A. Emadi, "Energy storage systems for automotive applications," IEEE Trans. Ind. Electron., vol. 55, no. 6, pp. 2258-2267, Jun. 2008.

[11] W. Jiang and B. Fahimi, "Multiport power electronic interface: Concept, modeling and desig," IEEE Trans. Power Electron., vol. 26, no. 7, pp. 1890-1900, Jul. 2011.

[12] - "Active current sharing and source management in fuel cellbattery hybrid power system," IEEE Trans. Ind. Electron., vol. 57, no. 2, pp. 752-761, Feb. 2010

[13] N. Femia, G. Petrone, G. Spagnuolo, and M. Vitelli, "A technique for improving p\&o mppt performances of double stage grid-connected photovoltaic systems," IEEE Trans. Ind. Electron., vol. 56, no. 11, p. 4473C4482, Nov. 2009.

[14] A. Emadi, "Modeling of power electronic loads in ac distribution systems using the generalized state-space averaging method," IEEE Trans. Ind. Electron., vol. 51, no. 5, pp. 992-1000, Oct. 2004.

[15] E. I. Ortiz-Rivera and F. Z. Peng, "Analytical model for a photovoltaic module using the electrical characteristics provided by the manufacturer data sheet," $36^{\text {th }}$ IEEE Power Electronics Specialists Conference, pp. 2087-2091, Jun. 2005. 